Research report

\title{
Massed but not spaced training impairs spatial memory
}

\author{
Sean Commins*, Lorretto Cunningham, Deirdre Harvey, Derek Walsh \\ Department of Psychology, National University of Ireland, Maynooth, Co. Kildare, Ireland
}

Received 10 June 2002; received in revised form 16 August 2002; accepted 16 August 2002

\begin{abstract}
The Morris water maze and the object displacement task are two popular tools used to investigate spatial learning and memory. Research has focused mainly on the acquisition of spatial tasks while little attention has been given to the retention phase. We examined the effects of different training procedures on retention of the water maze and also reactivity to spatial change in the object displacement task 7 days post-acquisition. We found that massed-trained animals were impaired on retention of the water maze compared to those animals that had received spaced-training. We also found that the massed-trained animals habituated readily to their environment in the object displacement task while the spaced-trained group did not. Furthermore the massed-trained group did not react to spatial change 7 days post-habituation compared to the increased reactivity displayed by the spaced-trained group. Results are discussed in terms of poor encoding of the environment leading to poor retention.
\end{abstract}

(C) 2002 Elsevier Science B.V. All rights reserved.

Keywords: Spatial memory; Spaced; Massed; Water maze; Object displacement

\section{Introduction}

One popular tool described 20 years ago to investigate spatial learning and memory is the Morris Water Maze (MWM) $[9,10]$. Its simplicity and the possibility to differentiate between the spatial learning (invisible platform) and non-spatial (visible platform) conditions is one of its main advantages [2]. Much of the research has focused on the acquisition phase of such a task [2]. There is, however, variation in the training schedules employed by different laboratories during acquisition. Brandner et al. [1] for example used 36 acquisition trials over 5 days, others only use 20 trials over 4 days (for example [19]). These different training procedures may highlight different encoding and consolidation processes [21]. Rats can acquire spatial tasks with massed training, that is training on a certain number of trials with short inter-trial intervals [24]. This training is considered to involve an encoding process based on spatial working memory [11,24]. Rats can also acquire spatial tasks with spaced training, that is training with a certain number of

\footnotetext{
* Corresponding author. Tel.: +353-1-7086-182; fax: +353-1-7084767

E-mail address: sean.commins@may.ie (S. Commins).
}

trials with large inter-trial intervals [16]. This procedure may involve an encoding process also based on spatial working memory but with the addition of long-term memory [11] and consolidation processes [21]. Comparisons of massed and spaced training have produced conflicting results. Goodrick [4] for example, demonstrated that rats that were spaced-trained on the t-maze learned better than massed-trained animals. In the water maze task rats that received massed training had higher number of errors when compared to the spaced-trained group [6]. However, Spreng et al. [21] found no difference between training procedures on acquisition of the water maze. It has also been demonstrated that massed training impairs acquisition of the water maze only under certain conditions. These conditions may include the age of the animal [17]. Therefore, whether impairments observed are due to poor encoding of the environment or fatigue as in the case for aged animals or a stressful task such as the water maze [7,17] remains controversial.

In contrast to acquisition and encoding, retention of long-term spatial memories has received little attention. This is despite the importance of these processes in models of spatial navigation and spatial memory $[12,13]$. It has been demonstrated that different training sche- 
dules not only affect acquisition but also retention of spatial tasks. Spaced training for example facilitates retention of spatial navigation in the water maze [21]. This effect, however, is observed only on long-term and not short-term retention. The effect is also age-related affecting adult and not adolescent rats. We will use the water maze task to determine the effects of massedtrained animals compared to spaced-trained animals on retention 7 days post-acquisition. We hypothesise that animals that receive massed training will be impaired on retention of the location of the platform. The spacedtrained animals will encode the environment better leading to better retention.

In a second experiment we will further test spatial ability of animals by using an object-displacement task [14]. This task examines exploration, spatial encoding and reactivity to spatial novelty. It is generally thought that this task is designed to estimate the ability of animals to encode spatial relationships among stimuli $[14,22,23]$. Furthermore, renewal of exploration after spatial rearrangement implies that the second arrangement is compared with an internal representation of the first arrangement and indicates the ability of animals to acquire and retain spatial knowledge [5]. We will use the object displacement task to determine the effects of massed-trained animals compared to spaced-trained animals on retention of an environment. An increased reaction to a spatial change should indicate a better encoding of the initial environment leading to better retention. This task will also eliminate any fatigue effects that might confound the water maze task. Finally this task will examine the differences in exploratory and encoding processes in massed compared to spacedtrained animals. We hypothesies that in the object displacement task both groups will habituate to the environment, although the spaced-trained group may habituate at a slower rate than the massed-trained group. We also hypothesies that the spaced-trained animals will react to the changed environment stronger than the massed-trained group.

\section{Method}

\subsection{Experiment 1}

\subsubsection{Animals}

Male Wistar rats (200-300 g; Bioresources Unit, University of Dublin, Trinity College) aged approximately 3 months were used as subjects. Rats were housed three per cage and were kept in a temperaturecontrolled room which was maintained on a fixed lightdark cycle. All rats were given free access to food and drink. All rats were well handled before experimentation and testing was carried out during the light phase.

\subsubsection{Apparatus and procedure}

The watermaze was a black circular pool $(1.7 \mathrm{~m}$ diameter; $35 \mathrm{~cm}$ deep; water $20 \pm 1{ }^{\circ} \mathrm{C}$ ) filled to $31 \mathrm{~cm}$. Rats can escape the water by climbing on to a hidden platform $(29 \mathrm{~cm} \times 9 \mathrm{~cm})$. The hidden platform was placed in the North Eastern quadrant of the pool and submerged $2 \mathrm{~cm}$ below water surface so it was invisible at water level; the location of the platform was fixed during the experiment. A curtain surrounded the water maze at a distance of $50 \mathrm{~cm}$ from the pool wall. Distal cues included two $(60 \mathrm{~W})$ lights suspended from the ceiling. One light was suspended from the NE corner, and the other from the NW position. Both lights were at a distance of $75 \mathrm{~cm}$ from the pool wall and at angles of approximately $60^{\circ}$. A rectangular sheet of black paper $(55 \mathrm{~cm} \times 81 \mathrm{~cm})$ stuck to the curtain on the eastern side of the pool was also used as a cue. A computerised digital tracking system (EthoVision) recorded escape latencies and velocity during each trial (Noldus Information Technology, Wageningen, Netherlands).

Rats were randomly assigned to one of two groups:

Group 1: massed trained group $(n=6)$. Rats were placed into the water maze for 16 consecutive trials. Rats were allowed $60 \mathrm{~s}$ to find the platform; otherwise the rat was led to the platform by the researcher. The rat remained on the platform for $20 \mathrm{~s}$. The intertrial interval was $10 \mathrm{~s}$. All rats entered the maze from a pseudo-random starting position (North, South, East or West).

Group 2: spaced trained group $(n=6)$. Rats received 4 trials/day for 4 days. Rats were again allowed $60 \mathrm{~s}$ to find the platform and allowed to remain on the platform for $20 \mathrm{~s}$. The inter-trial interval again was 10 s. All rats entered the maze from a pseudo-random starting position (North, South, East or West).

Various behavioural criteria were used to measure acquisition including escape latency and velocity. Retention was assessed 7 days after the end of the acquisition phase. Retention for both groups was assessed by removing the platform. The rat was then placed into the water maze from the South starting position and allowed to swim for $60 \mathrm{~s}$. Percentage time spent in the platform area (on total time spent in the pool, i.e. $60 \mathrm{~s}$ ) was used to measure retention. This was defined by a circular area centred at the platform with a radius of approximately $27 \mathrm{~cm}$ (body length of a rat). Percentage time spent (again on total time spent in the pool) in three other equivalent locations (NW, SW and SE) was also calculated. 


\subsection{Experiment 2}

\subsubsection{Animals}

Male Wistar rats (200-300 g; Bioresources Unit, University of Dublin, Trinity College) aged approximately 3 months were again used as subjects. Rats were housed three per cage and were kept in a temperaturecontrolled room which was maintained on a fixed lightdark cycle. All rats were given free access to food and drink. All rats were well handled before experimentation and testing was carried out during the light phase.

\subsubsection{Apparatus}

The apparatus consisted of a black circular fiberglass arena (diameter $=130 \mathrm{~cm}$, height $=38 \mathrm{~cm}$ ) resting on a table $70 \mathrm{~cm}$ above the ground and illuminated from above by a single lamp. Curtains surrounded the entire arena. During testing the experimenter, wearing a white laboratory coat stood at the side of the arena. Four objects were placed in a square formation at the center of the arena approximately $40 \mathrm{~cm}$ apart (see Fig. 1). The four objects included a rectangular plastic box $(13.5 \mathrm{~cm}$ height $\times 27 \mathrm{~cm}$ length $\times 11 \mathrm{~cm}$ width), a concrete pillar $(18.5 \mathrm{~cm}$ height $\times 12.5 \mathrm{~cm}$ diameter), a wooden tree stump (12 cm height $\times 8 \mathrm{~cm}$ diameter) and a plant in a glass vase $(33 \mathrm{~cm}$ height $\times 10.5 \mathrm{~cm}$ diameter $)$.

\subsubsection{Procedure}

Initially, each rat was allowed $1 \mathrm{~min}$ to explore the empty arena. The experimenter did not stand with the curtains during this phase. The four objects were then positioned (see Fig. 1).

Rats were randomly assigned to one of two groups:

Group 1: massed trained group $(n=6)$. Rats were placed in the center of the arena and given four consecutive trials to explore the arena. Each trial lasted $3 \mathrm{~min}$. The inter-trial interval was approximately $20 \mathrm{~min}$.

Group 2: spaced trained group $(n=6)$. Rats received $1 \mathrm{trial} /$ day for 4 days. Each trial again lasted $3 \mathrm{~min}$.

Various behavioural criteria were used to assess exploratory behaviour. The experimenter recorded the number of nose contacts each rat made with the individual objects. The path length of each rat was also recorded by a computerised digital tracking system (EthoVision). Retention was assessed 7 days after the end of acquisition. This consisted of a single trial (3-min duration) where the wooden block was moved towards the side of the arena (see Fig. 1). To eliminate the possible biasing factor of any olfactory cues, the experimenter handled every object.

\subsubsection{Statistics}

A series of repeated ANOVAs were used. Where appropriate independent and/or dependent $t$-tests were also used. All statistics were carried out using SPSS (version 10).

\section{Results}

\subsection{Experiment 1}

\subsubsection{Water maze acquisition}

Both the massed-trained group and the spacedtrained group acquired the water maze. Fig. 2a demonstrates that the mean escape latencies decreased over the 16 trials (averaged over four trials) for the massedtrained group. Fig. 2a also displays a decrease in escape latency for the spaced-trained group. A two-way repeated measures ANOVA with training condition (massed vs. spaced) as the between-group measure and acquisition session as the within-group measure revealed

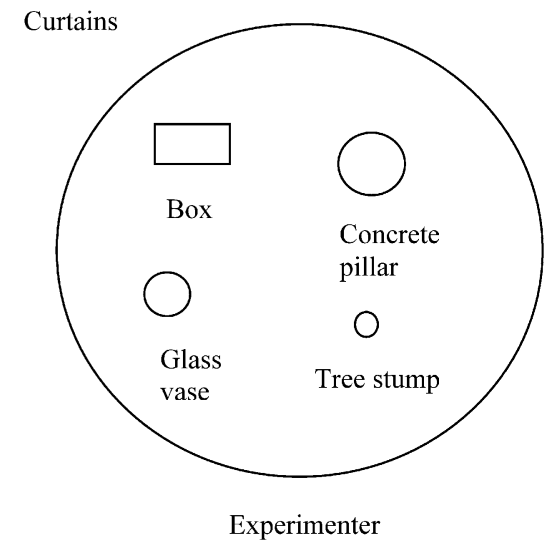

Acquisition

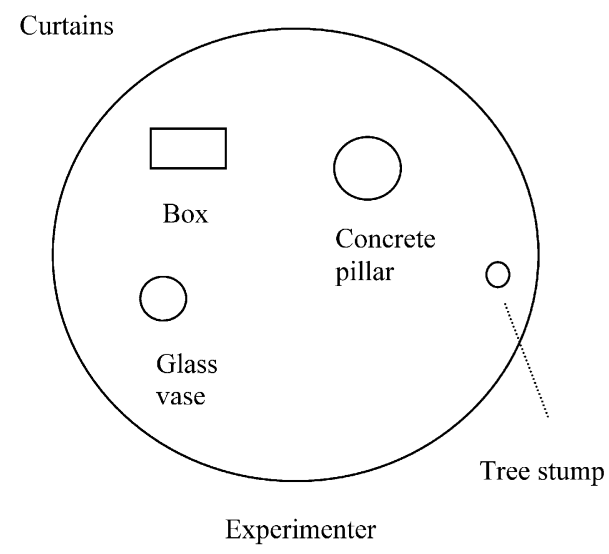

Retention

Fig. 1. Layout of the environment in experiment 2 during habituation (acquisition) and retention phase. 


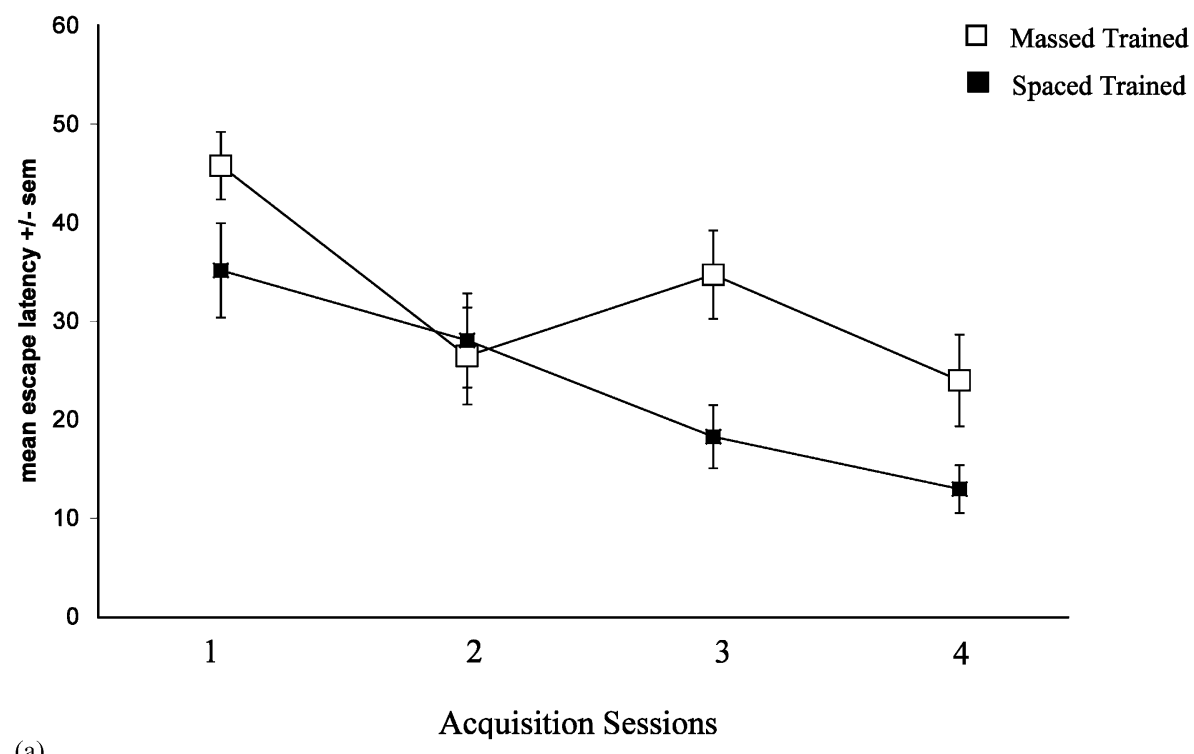

(a)

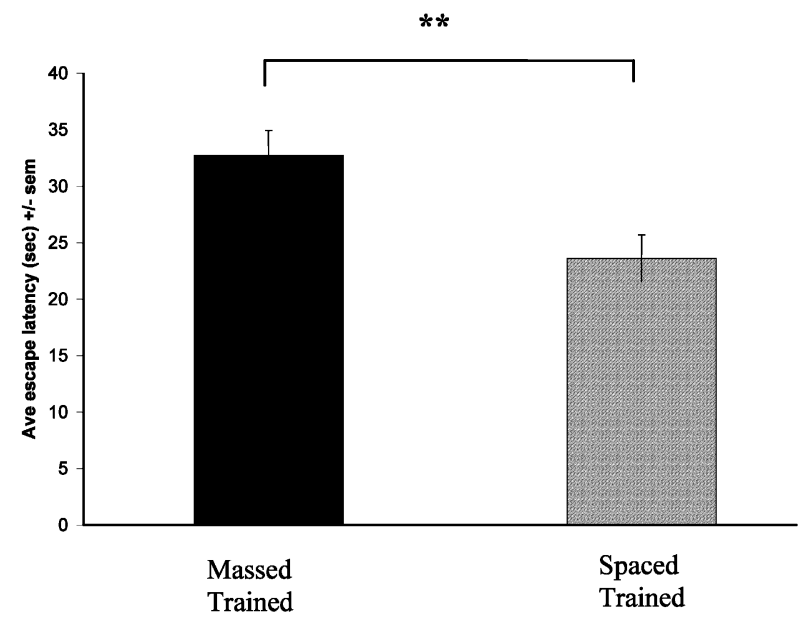

(b)

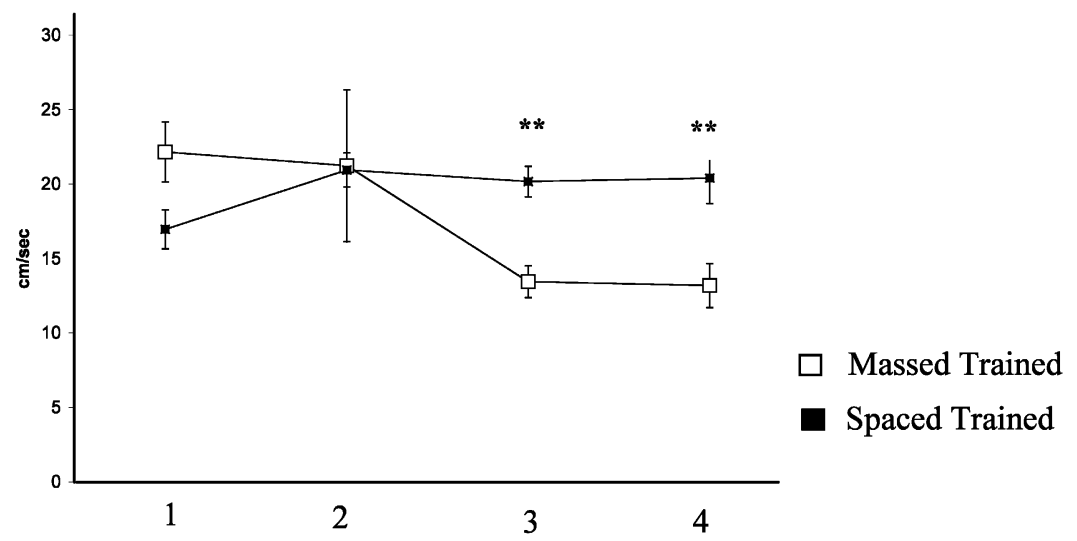

(c)

Acquisitions Sessions

Fig. 2 
a significant effect of training condition (see Fig. 2b; $F=9.191, \mathrm{df}=1,177, p<0.01)$. This demonstrates that the spaced-trained group had lower escape latencies than the massed-trained group. There was also a significant effect of acquisition session $(F=8.919, \mathrm{df}=$ $3,177, p<0.01)$. There was, however, no interaction effects.

Fig. 2c demonstrates a decrease in velocity over the 16 trials (averaged over four trials) for the massed-trained group. The mean velocity for the first four trials was $22.15 \pm 2.01 \mathrm{~cm} / \mathrm{s}$. This decreased to $13.18 \pm 1.46 \mathrm{~cm} / \mathrm{s}$ for the final four trials. In comparison, the velocity of the spaced-trained group on the first day of acquisition was $16.95 \pm 1.3 \mathrm{~cm} / \mathrm{s}$. This increased to $20.39 \pm 1.7 \mathrm{~cm} / \mathrm{s}$ on the final day of acquisition. A repeated-measures ANOVA with training condition as the between-group measure and acquisition session as the within-group measure revealed a non-significant effect of training condition $(F=1.648, \mathrm{df}=1,177 p>0.05)$, and a nonsignificant effect of acquisition session $(F=1.687, \mathrm{df}=$ $3,177, p>0.05)$. However, there was a significant Condition $\times$ Session interaction $(F=3.295, \mathrm{df}=3,177$, $p<0.05)$. Subsequent $t$-test analysis for between conditions revealed that the massed-trained group was significant slower than the spaced-trained group (see Fig. 2c) on acquisition sessions 3 and $4(t=4.54$, df $=$ $46, p<0.01 ; t=2.881, \mathrm{df}=46, p<0.01$, respectively).

\subsubsection{Retention of water maze}

Fig. 3a reveals that animals that were spaced-trained spent significantly more time swimming in the platform area (NE, $17.57 \pm 3.7 \%)$ than animals that were massedtrained $(6.6 \pm 2.6 \%)$. An independent $t$-test confirmed this finding; $t=-2.39, \mathrm{df}=10, p<0.05$. There were no significant differences in the amount of time spent swimming by either group in any of the other 3 equivalent areas $(t=0.452, \quad \mathrm{df}=10, p>0.05 ; t=$ $-0.691, \mathrm{df}=10, p>0.05, t=0.432, \mathrm{df}=10, p>0.05$; SW, SE, NW areas, respectively). Fig. $3 \mathrm{~b}$ shows representative swim paths taken by both massed- and spaced-trained groups during the retention trial.

\subsection{Experiment 2}

\subsubsection{Habituation}

Fig. 4a shows that animals that were given 4 sequential trials (massed-trained) habituated rapidly to the environment. The number of nose contacts made with the 4 objects decreased from $35.5 \pm 3.7$ on the first trial to $16 \pm 1.9$ on the fourth trial. This habituation was confirmed by a one-way ANOVA. There was an overall significant difference between the trials $(F=11.522$, $\mathrm{df}=3,20, p<0.001$ ). Subsequent post-hoc tests (Tukey, $p<0.05)$ revealed that there were fewer nose contacts with the objects on trial 4 compared to trials 1 and 2 . There were also significantly fewer nose contacts on trial 3 when compared to trial 1 . In contrast animals that were exposed to the environment for one trial for each of 4 days (spaced-trained) did not habituate (see Fig. 4a) to the environment. The number of nose contacts with the objects went from $22.16 \pm 2.57$ on day 1 to $18.33 \pm$ 2.1 on day 4. Again a one-way ANOVA was used to compare the number of nose contacts across days. No significant difference was found between days $(F=$ 0.404 , df $=3,20, p>0.05$ ) suggesting an absence of habituation.

In order to compare both groups across habituation trials a two-way repeated measures ANOVA was carried out with training condition (massed vs. spaced) as the between-group measure and trial number as the withingroup measure. This revealed a non-significant effect of training condition (see Fig. $4 \mathrm{~b} ; F=3.708$, df $=1,10$, $p>0.05$ ). This suggests that the average number of contacts made by either group was similar over the habituation period. There was a significant effect of trial number $(F=9.201, \mathrm{df}=3,30, p<0.01)$ and also a significant Condition $\times$ Trial effect $(F=5.261$, df $=3$, $30, p<0.01)$. Subsequent t-test analyses for betweengroup differences revealed that the massed-trained group made significantly more nose contacts with the objects on trial 1 than the spaced-trained group $(t=$ $-2.909, \mathrm{df}=10, p<0.05)$. No other differences were noted.

Further analysis revealed no significant difference ( $t=-0.705, \mathrm{df}=46, p>0.05$, see Fig. $4 \mathrm{c})$ between the groups on the average path length over the habituation period $(1627.4 \pm 77$ vs. $1708.3 \pm 84.9 \mathrm{~cm}$ massed and spaced groups, respectively).

\subsubsection{Reaction to a displaced object}

Reaction to a displaced object (spatial novelty) was assessed 7 days post-habituation. Fig. 5a reveals that animals that were spaced-trained made a significantly higher number of nose contacts with all objects when compared to the animals that were massed-trained $(t=$ $-3.045, \mathrm{df}=10, p=0.01)$. This is despite similar path lengths recorded by the two groups $(t=-0.830, \mathrm{df}=9$, $p>0.05$, data not shown).

We then compared the number of nose contacts made with all the objects on the final day of habituation to those on the retention trial. A repeated measures ANOVA was conducted for the massed-trained animals.

Fig. 2. (a) Mean escape latency ( $\mathrm{s} \pm$ S.E.M.) for massed-trained group and spaced-trained group during acquisition of the water maze task. Averages of four trials are plotted for the massed-trained group. (b) A bar chart displaying the mean escape latencies for both massed- and spaced-trained groups over the total acquisition period. (c) Total velocity ( $\mathrm{cm} / \mathrm{s} \pm$ S.E.M.) of each group within $60 \mathrm{~s}$ allowed across the acquisition period. 

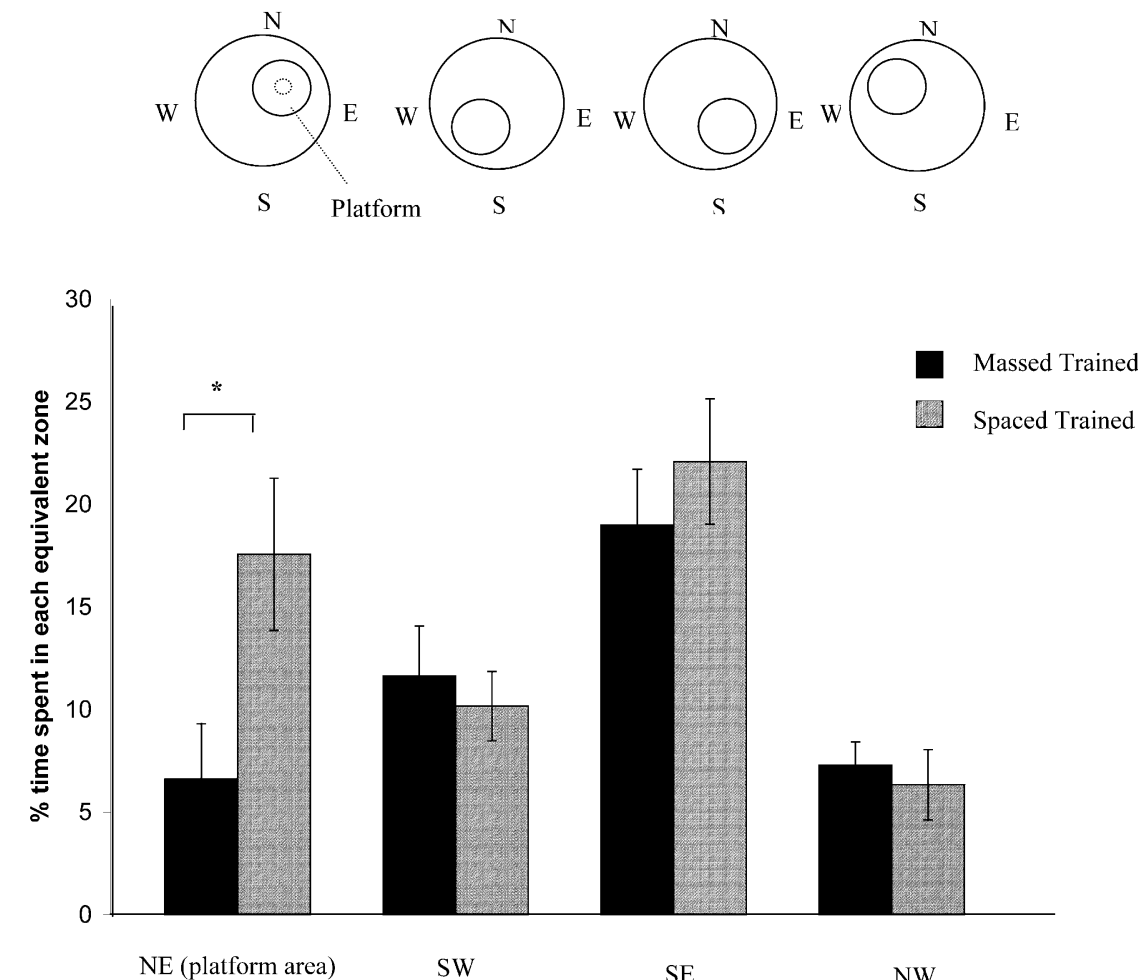

(a)

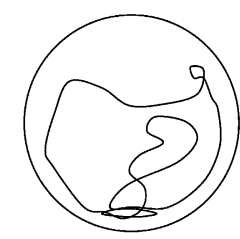

Massed

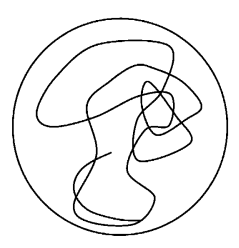

Spaced

Fig. 3. (a) A bar chart displaying the mean percentage time \pm S.E.M. spent in the platform area (NE) and the three other equivalent areas (SW, SE, NW) for both massed- and spaced-groups on the retention phase. (b) Representative swim paths for both groups are also displayed.

Object type (wood, plant, box and pillar) was used as the between-group measure and day (final day vs. retention) as the within-group measure. This revealed a nonsignificant effect of day (Fig. $5 \mathrm{~b}, F=0.244$, df $=1,20$, $p>0.05)$. There was a significant effect of object type $(F=4.274, \mathrm{df}=3,20, p<0.01)$. There was also a significant Object $\times$ Day interaction effect $(F=3.833$, $\mathrm{df}=3,20, p<0.01)$. However, subsequent $t$-test analyses revealed no significant between-group differences (see Fig. 5c). A further repeated measures ANOVA was conducted for the spaced-trained animals. Object type was again used as the between-group measure and day as the within-group measure. This revealed a significant effect of day (Fig. 5b, $F=6.64$, df $=1,20, p<0.01$ ). There was a non-significant effect of object type $(F=$ $0.734, \mathrm{df}=3,20, p>0.05$ ). There was also a significant Object $\times$ Day interaction effect $(F=5.006, \mathrm{df}=3,20$, $p<0.001)$. Subsequent t-test analyses for between- group differences revealed that the number of nose contacts made by the spaced-trained group with the displaced object (wood) significantly increased (Fig. 5d, $t=-4.842, \mathrm{df}=5, p<0.001)$ on the retention trial when compared to the final day of habituation. No other differences were noted.

\section{Discussion}

The experiments presented in this paper demonstrate that massed training impairs the ability of animals to retain a spatial memory of an environment. We have shown that animals that received massed training in the water maze subsequently spent significantly less time in the platform area compared to the animals that received spaced training. We have shown that the massed-trained animals were also slower to acquire the task both in 

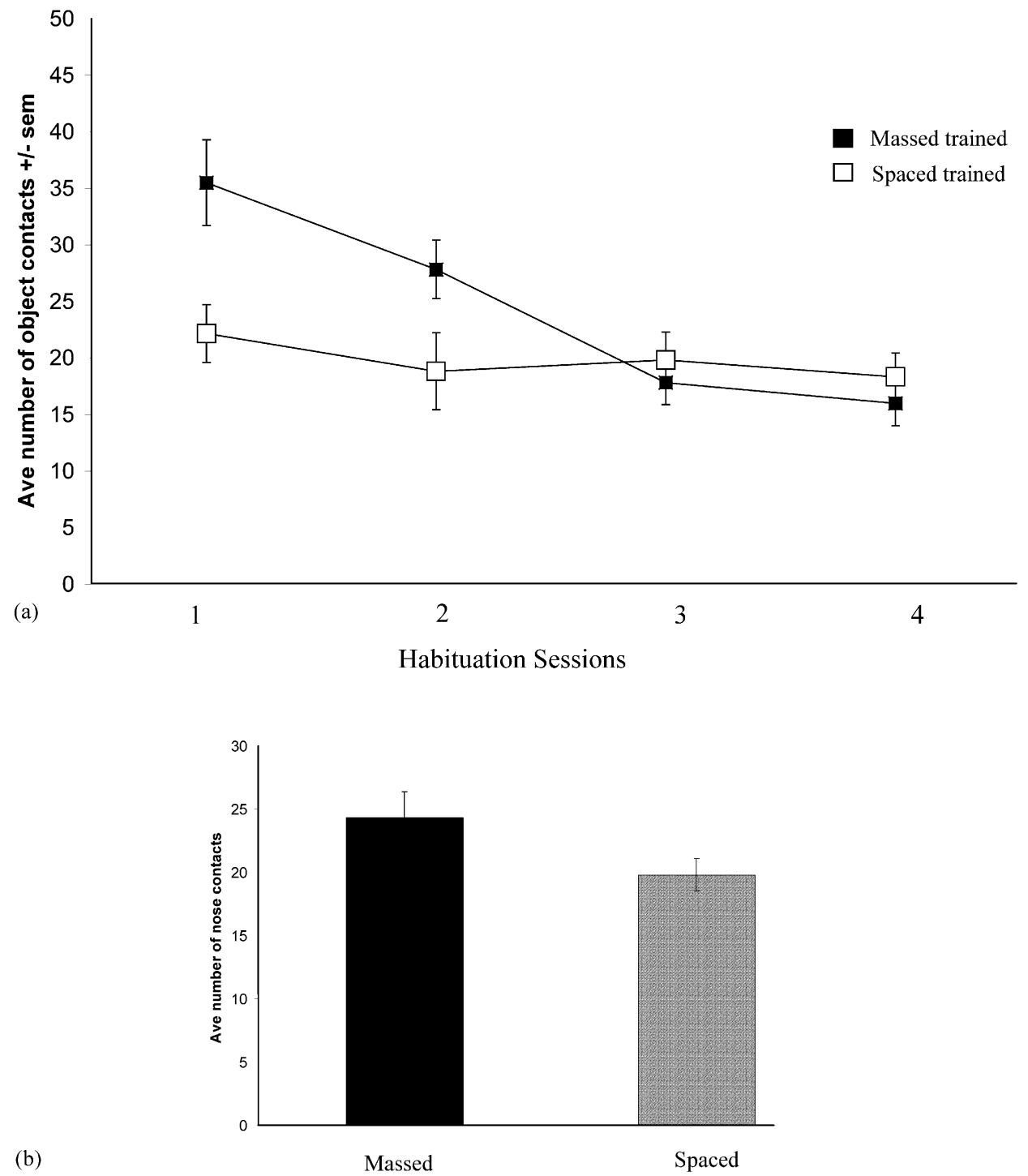

(b)

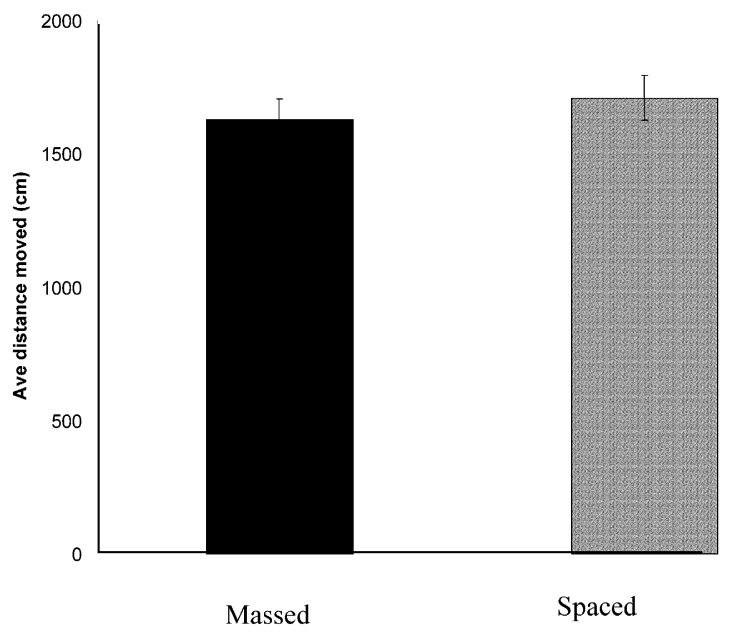

Fig. 4. (a) Exploration and habituation patterns for massed- and spaced-trained groups. (b) A bar chart displaying the average number of nose contacts made with all objects over the total habituation period. (c) A bar chart displaying average distance moved for both groups over the total habituation period. 


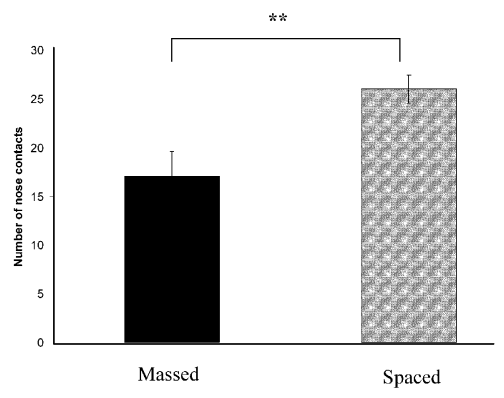

(a)

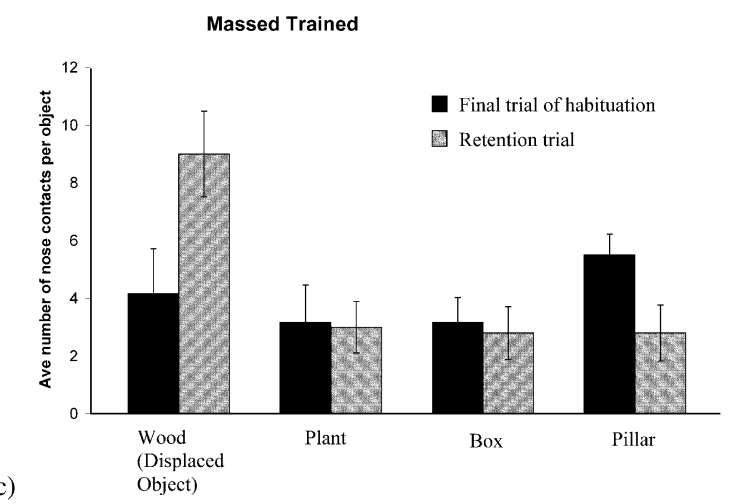

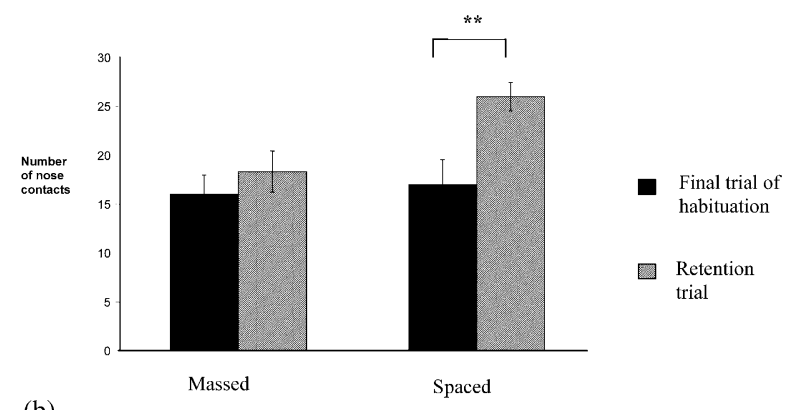

(b)

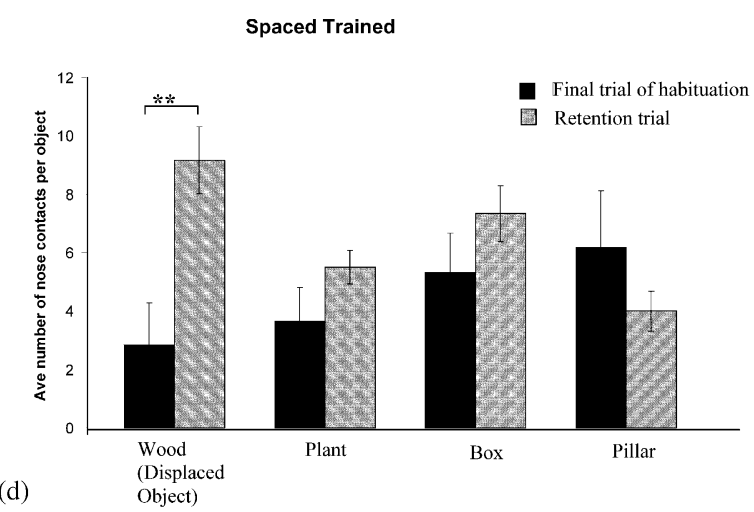

Fig. 5. (a) A bar chart displaying the reactivity to all objects by massed- and spaced-trained groups during the retention phase. (b) A bar chart displaying average number of contacts made with all objects by both groups on the final day of habituation compared with the retention trial. (c) A bar chart displaying reaction to each object by the massed-trained group on the final day of habituation compared to the retention trial. (d). A bar chart displaying reaction to each object by the spaced-trained group on the final day of habituation compared to the retention trial.

terms of escape latency and velocity. Fatigue problems may account for poor retention. Although fatigue has been shown to be a source of behavioural impairment in some animals [7,17], Spreng et al. [21] did not detect any such manifestations. Instead these authors suggest that long-term retention impairments result from the lack of occasions for consolidation processes. This suggestion is similar to that provided by Morris and Doyle [11] who accounted for the differences between massed and spaced-trained animals in terms of working and longterm memory differences. These suggestions may indeed contribute to the poor retention performance of the massed-trained animals but we would also attribute the impairment to poor encoding of the initial environment. This can be seen in the object displacement task.

The object displacement task requires animals to retain the spatial arrangement of the environment. Exploratory behaviour is a natural activity during which animals acquire spatial information about their environment [5]. When an animal is placed into an environment they explore it and any objects that may be present [14,15]. This exploration decreases over time as long as no change occurs [5]. We demonstrated that animals exposed to an environment with short inter-trial intervals (massed trained) habituate normally and their exploration of the environment decreases over trial number. However, animals that had $24 \mathrm{~h}$ between trials (spaced-trained) did not habituate and renewed their exploratory activity each day. Although the massedtrained animals made more nose contacts on the first trial of habituation compared to the spaced-trained group, this did not affect the overall habituation pattern. The habituation pattern still was evident from the second trial where no group differences were noted. Similarly Espejo [3] reports that repeated exposure to the elevated plus-maze does not lead to habituation of exploratory or locomotor responses if tested either weekly or daily. We suggest that as the spaced-trained animals did not habituate, they renewed their exploration and built up a better spatial representation. This suggestion can be seen in studies involving aged animals. Shukitt-Hale et al. [20] for example have demonstrated that old rats explored objects less than young rats and have decrements in the ability to build spatial representations of the environment and to use this information to detect changes in new spatial arrangements. The opposite also seems to hold true. 5-HT1B knock-out mice for example, show increased exploratory activity and also increased memory performance in the water maze [8]. It should be noted however that exploratory 
activity is strain-dependent [18] and care should be taken when comparing studies.

This paper also demonstrates that animals that were spaced-trained displayed an increased reaction to the new spatial environment compared to the massedtrained animals. We observed that there is a general increase in reactivity to all objects in the spaced-trained animals. Furthermore, this group displayed an increased reaction to the object itself that was displaced. Lack of exploration has been found to correlate with a failure to react to spatial change in old animals [25]. These authors argue that lack of spatial reactivity shown by an absence of exploration renewal occurs when there is no discordance between the two arrangements (before and after the object is displaced). We would also argue that better encoding of the environment leads to better retention and therefore an increased reactivity to a new spatial arrangement.

\section{Acknowledgements}

This work was supported by the Health Research Board and the Department of Psychology, NUI Maynooth. We thank Shane O'Mara (Trinity College, Dublin) for helpful discussions.

\section{References}

[1] Brandner C, Vantini G, Schenk F. Postnatal intracerebroventricular administrations of NGF alter spatial memory in adulthood. Behav Brain Res 2000;111:165-73.

[2] D'Hooge R, De Deyn PP. Applications of the Morris water maze in the study of learning and memory. Brain Res Rev 2001;36:6090.

[3] Espejo EF. Effects of weekly or daily exposure to the elevated plus-maze in male mice. Behav Brain Res 1997;87:233-8.

[4] Goodrick CL. Maze learning of mature-young and aged rats as a function of distributed practice. J Exp Psychol 1973;98:344-9.

[5] Granon S, Save E, Buhot M-C, Poucet B. Effortful information processing in a spontaneous spatial situation by rats with medial prefrontal lesions. Behav Brain Res 1996;78:147-54.

[6] Hasegawa N, Shimamura K, Suzuki K. Studies on the development of water maze-learning ability in rats (3). Effects of the learning schedule on learning acquisition. Jikken Dobutsu 1988;37:297-301.

[7] Ivy GO, Rick JT, Murphy MP, Head E, Reid C, Milgram NW. Effects of L-deprenyl on manifestations of aging in the rat and dog. Ann N Y Acad Sci 1994;717:45-59.

[8] Malleret G, Hen R, Guillou JL, Segu L, Buhot MC. 5-HT1B receptor knock-out mice exhibit increased exploratory activity and enhanced spatial memory performance in the Morris water maze. J Neurosci 1999;19:6157-68.

[9] Morris RGM. Spatial localisation does not require the presence of local cues. Learn Motiv 1981;12:239-60.

[10] Morris RGM. Development of the water maze procedure for studying spatial learning in the rat. J Neurosci Methods 1984;11:47-60.

[11] Morris RGM, Doyle J. Successive incompatible tasks: evidence for separate subsystems for storage of spatial knowledge. In: Buzsaki G, Vanderwolf $\mathrm{CH}$, editors. Electrical activity of the archicortex. Budapest: Akademiai Kiado, 1985.

[12] Nadel L, Samsonovich A, Ryan L, Moscovitch M. Multiple trace theory of human memory: computational, neuroimaging, and neurophysiological results. Hippocampus 2000;10:352-68.

[13] O'Keefe J, Nadel L. The hippocampus as a cognitive map. Oxford: Claredon Press, 1978.

[14] Poucet B. Object exploration habituation, and response to a spatial change following septal or medial frontal cortical damage. Behav Neurosci 1989;103:1009-16.

[15] Poucet B, Chapuis N, Durup M, Thinus-Blanc C. A study of exploratory behaviour as an index of spatial knowledge in hamsters. Anim Learn Behav 1986;14:93-100.

[16] Radish-Pour A, Montamedi F, Motahed-Larijani Z. Effects of reversible inactivations of the medial septal area on reference and working memory versions of the Morris water maze. Brain Res 1996;709:131-40.

[17] Rick JT, Murphy MP, Ivy GO, Milgram NW. Short intertrial intervals impair water maze performance in old Fischer 344 rats. J Gerontol Biol Sci 1996;51a:B253-60.

[18] Schmitt U, Hiemke C. Strain differences in open-field and elevated plus-maze behavior of rats without and with pretest handling. Pharmacol Biochem Behav 1998;59:807-11.

[19] Shaw KN, Commins S, O’Mara SM. Lipopolysaccharide causes deficits in spatial learning in the watermaze but not in BDNF expression in the rat dentate gyrus. Behav Brain Res 2001;124:4754.

[20] Shukitt-Hale B, Casadesus G, Cantuti-Castelvetri I, Joseph JA. Effect of age on object exploration, habituation, and response to spatial and nonspatial change. Behav Neurosci 2001;115:105964.

[21] Spreng M, Rossier J, Schenk F. Spaced training facilitates longterm retention of place navigation in adult but not in adolescent rats. Behav Brain Res 2002;128:103-8.

[22] Thinus-Blanc C, Durup M, Poucet B. The spatial parameter encoded by hamsters during exploration. Behav Process 1992;26:43-57.

[23] Usiello A, Sargolini F, Roullet P, Ammassari-Teule M, Oliverio A, Mele A. $N$-methyl-D-aspartate receptors in the nucleus accumbens are involved in detection of spatial novelty in mice. Psychopharmacology 1998;137:175-83.

[24] Van der Staay FJ, de Jonge M. Effects of age on water escape behaviour and on repeated acquisition in rats. Behav Neural Biol 1993;60:33-41.

[25] Van Waas M, Soffie M. Differential environmental modulations on locomotor activity, exploration and spatial behaviour in young and old rats. Physiol Behav 1996;59:265-71. 